
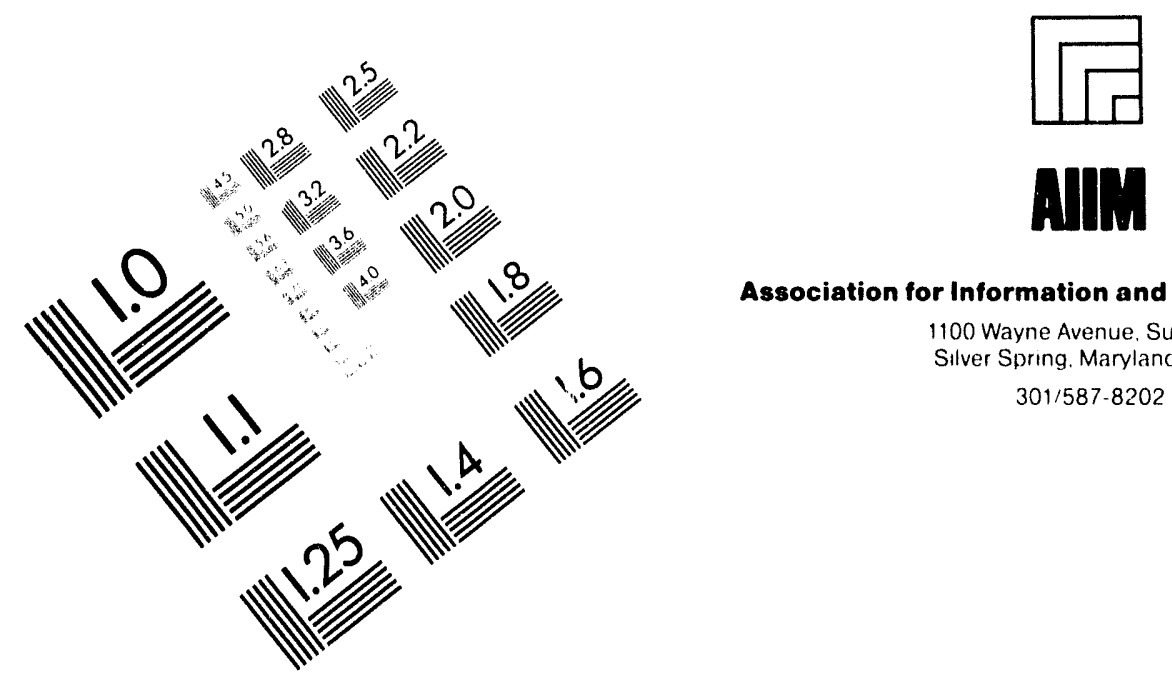

Association for Information and Image Management

1100 Wayne Avenue. Sulte 1100

Silver Spring. Maryland 20910

301/587-8202

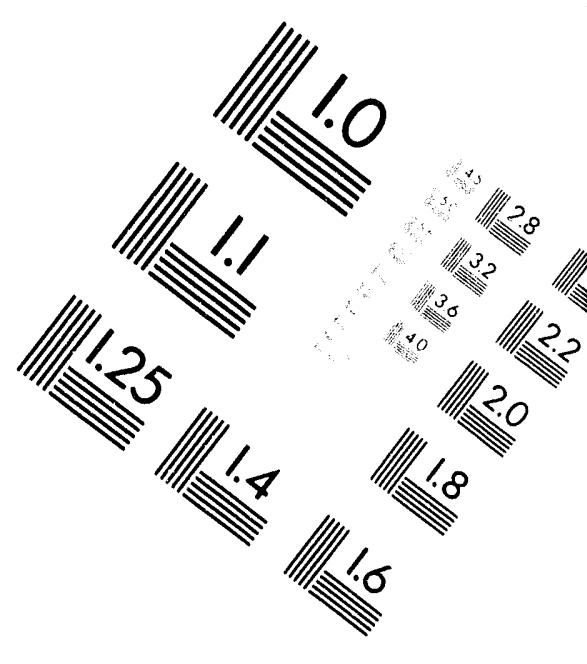

\title{
Centimeter
}

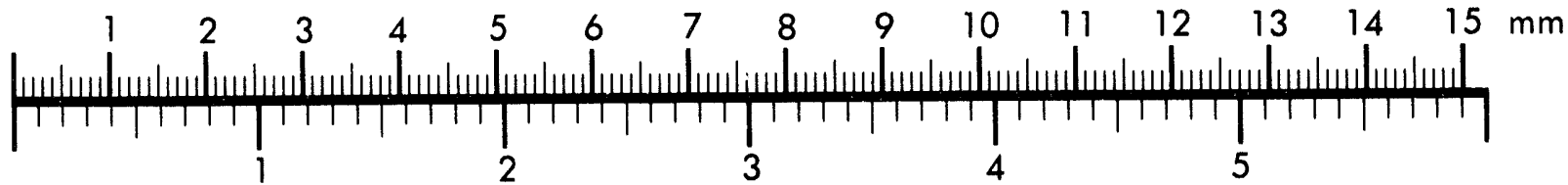

Inches
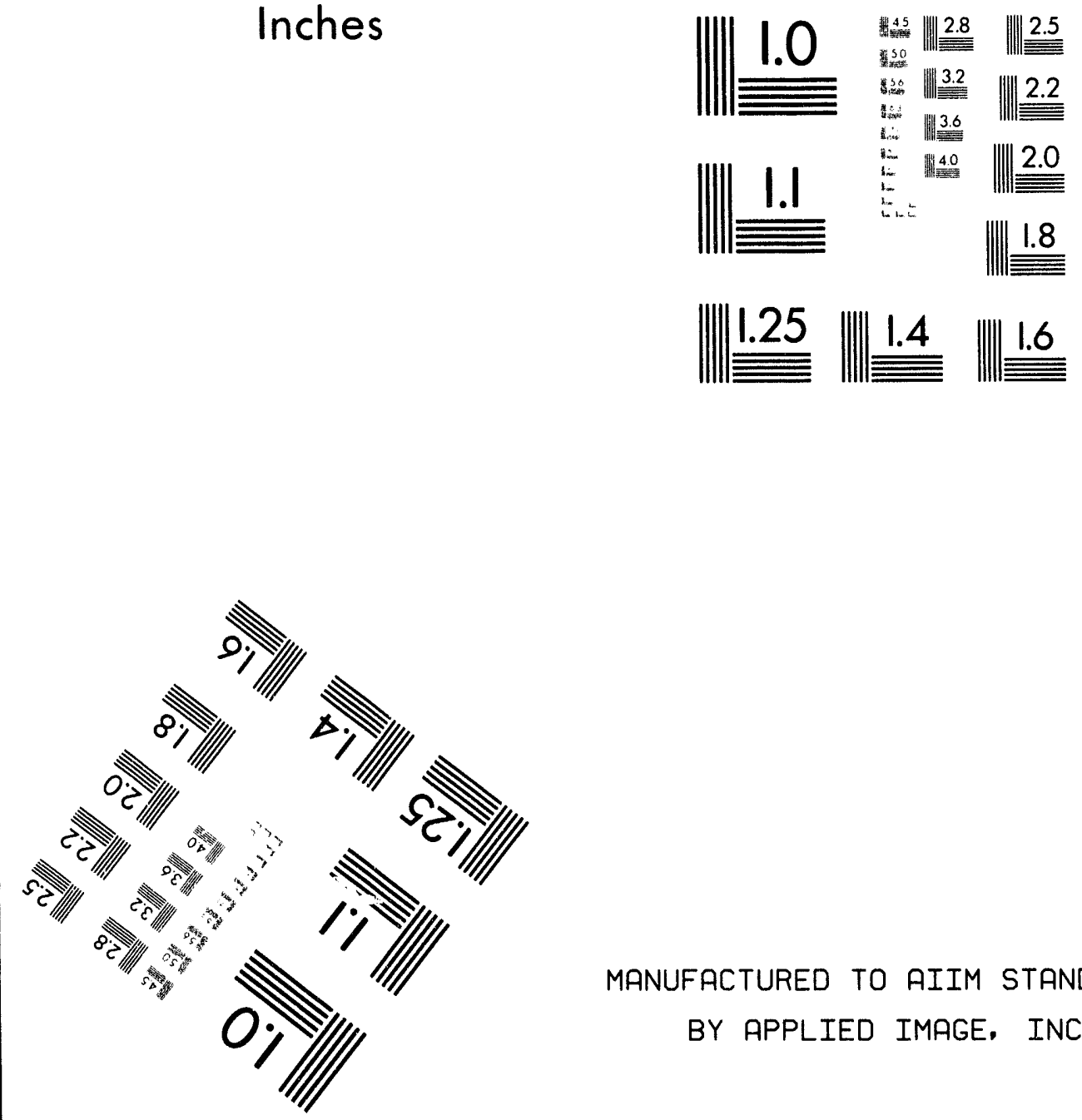

MANUFACTURED TO AIIM STANDARDS

BY APPLIED IMAGE, INC.

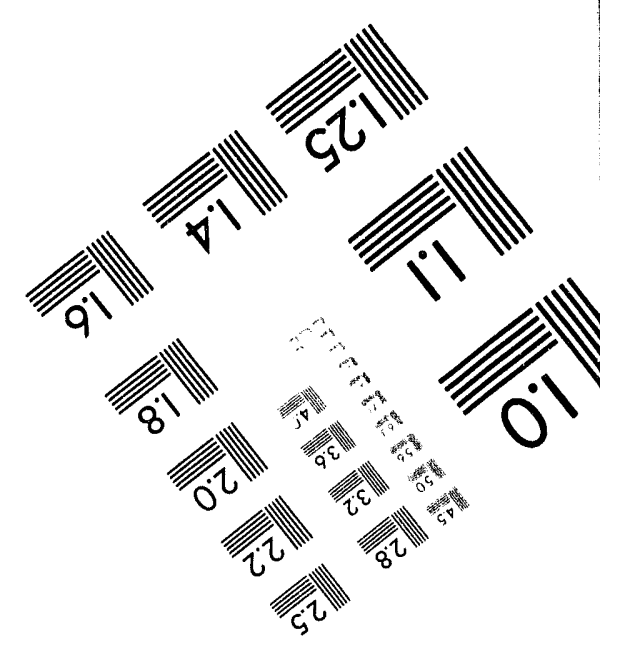



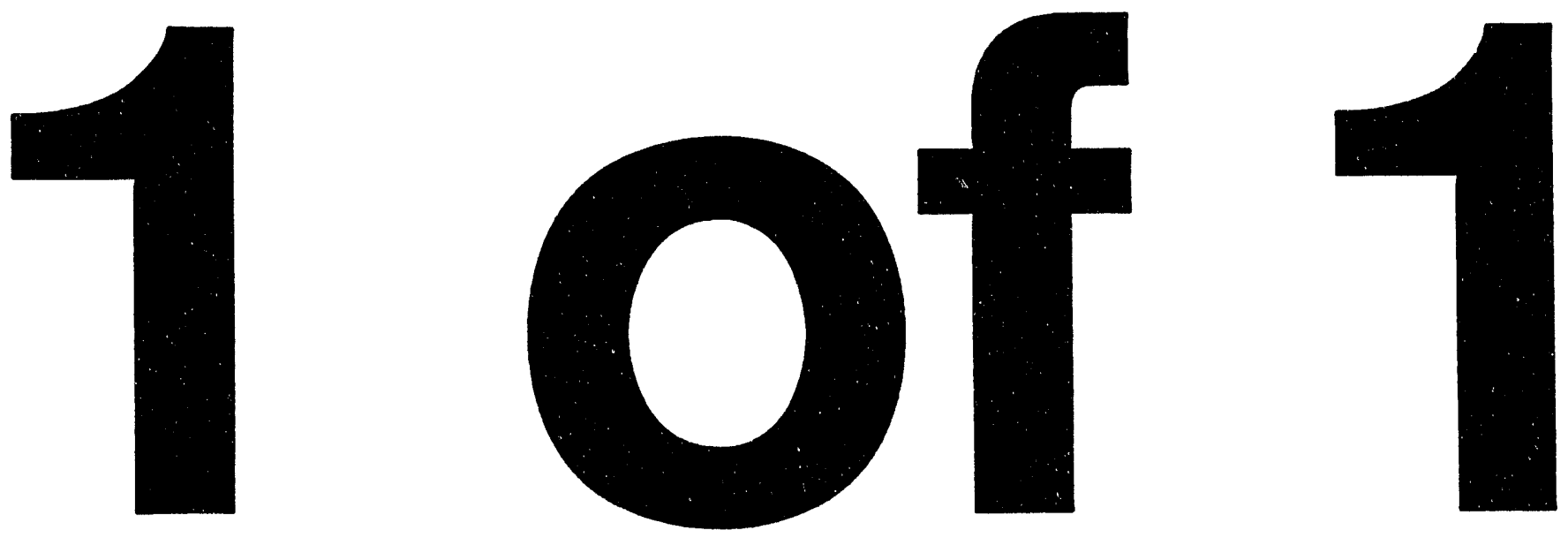


\section{KENO V.A CERTIFICATION PACKAGE}

by

\section{K. A. Niemer}

Westinghouse Savannah River Company

Savannah River Site

Aiken, South Carolina 29808

DOE Contract No. DE-AC09-89SR18035

This paper was prepared in connection with work done under the above contract number with the $U$. S. Department of Energy. By acceptance of this paper, the publisher and/or recipient acknowledges the U. S. Government's right to retain a nonexclusive, royalty-free license in and to any copyright covering this paper, along with the right to reproduce and to authorize others to reproduce all or part of the copyrighted paper. 
WSRC-TR-94-0193

\title{
KENO V.a CERTIFICATION PACKAGE (U)
}

\author{
By
}

KEYES A. NIEMER

\section{APRIL 1994}

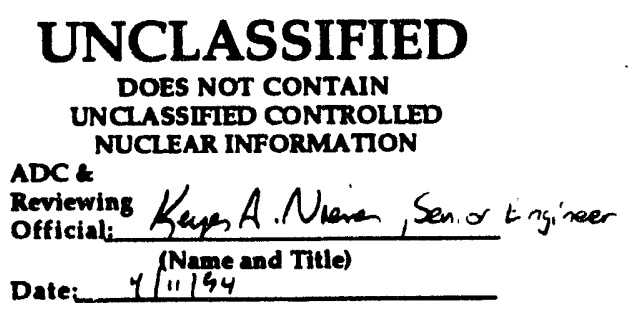

Westinghouse Savannah River Company Savannah River Site

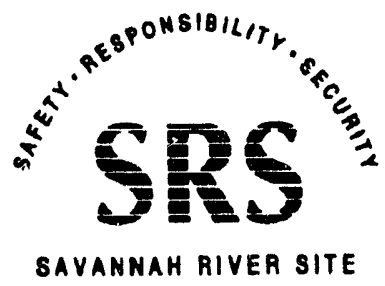
Aiken, SC 29808 


\section{DISCLAIMER}

This report was prepared by Westinghouse Savannah River Company (WSRC) for the Unifed States Department of Energy under Contract DE-AC09-88SR18035 and is an acsount of work performed under that Contract. Neither the United States, the United States Department of Energy nor WSRC, nor any of their employees, makes any warranty, express or implied, or assumes any legal liability or responsibility for the accuracy, completeness, or usefulness of any information, apparatus, product, or process disclosed herein, or represents that its use will not infringe privately owned rights. Reference herein to any specific commercial product, process or service by trade name, mark, manufacturer, or otherwise does not necessarily constitute or imply endorsement, recommendation, or favoring of same by WSRC or by the United States Government or any agency thereof. The views and opinions of authors expressed herein do not necessarily state or reflect those of the United States Government or any agency thereof. 
WSRC-TR-94-0193

SAFETY TECHNOLOGY DEPARTMENT

KEY WORDS: SCALE

KENO

Computer Codes

Cross Sections

Criticality

RETENTION PERIOD:

Permanent

\section{KENO V.a CERTIFICATION PACKAGE (U)}

By

KEYES A. NIEMER

ISSUED: April 1994

SAVANNAH RIVER TECHNOLOGY CENTER, AIKEN, SC 29808

Westinghouse Savannah River Company

Prepared for the U. S. Department of Energy under Contract DE-AC0988SR18035 
DOCUMENT: WSRC-TR-94-0193

TITLF: KENO V.a CERTIFICATION PACKAGE (U)

TASK: $\quad$ 93-006-N-A-1

TASK TITLE: SCALE 4.1 CRITICALITY CODE CERTIFICATION

APPROVALS

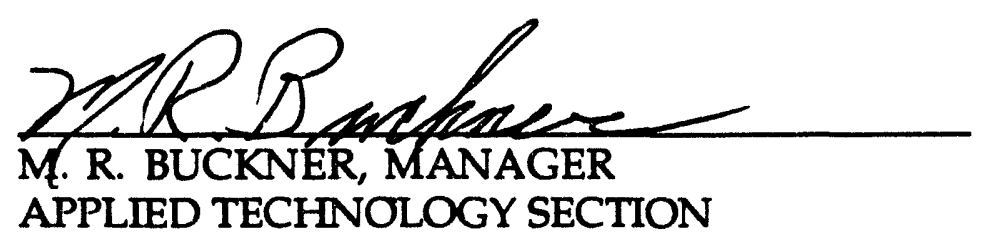

DATE: $\quad 4-27-94$

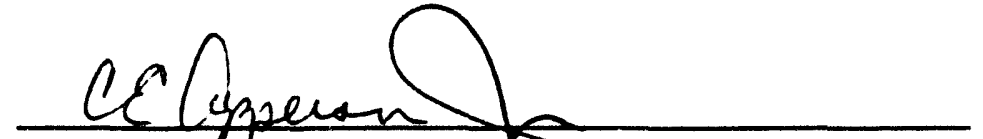

C. E. APPERSON, MANAGER APPLIED PHYSICS GROUP

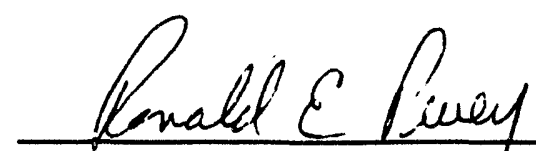

R. E. PEVEY, TECHNIC \&L REVIEWER

Keys A. Ninon

K. A. NIEMER, AUTHOR
DATE: $\quad 4-26-94$

DATE: $\quad 4 / 25 / 94$

DATE: $4 / 11 / 94$ 


\begin{abstract}
KENO V.a has been certified. KENO V.a is a multigroup Monte Carlo criticality program used to calculate the k-effective of a 3-D system. It is part of the SCALE

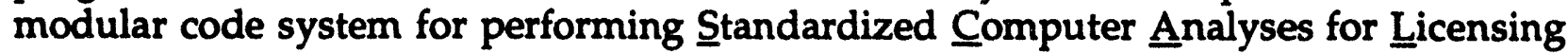
Evaluation. SCALE was developed for the Nuclear Regulatory Commission to satisfy a need for a standardized method of analysis for the evaluation of nuclear fuel facility and package designs. In its present form, the system has the capability to perform criticality, shielding, and heat transfer analyses using well established functional modules tailored to the SCALE system. KENO V.a will be used at SRS to perform critical calculations related to nuclear criticality safety.
\end{abstract}




\section{Table of Contents}

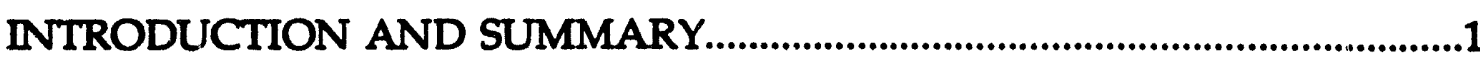

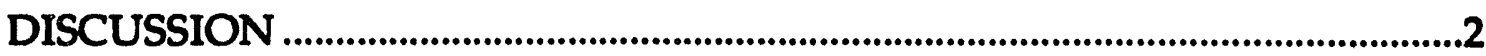

Application...........................................................................................

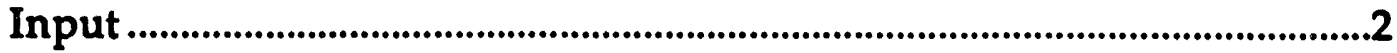

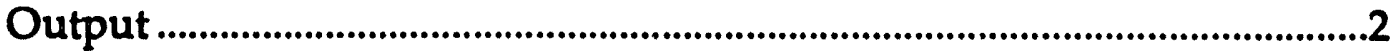

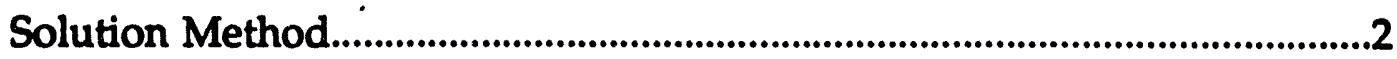

Accuracy and Limitations ..............................................................................2

Code Source Listing Location ..........................................................................2

Program Execution ....................................................................................................

Access Control and Security ...............................................................................

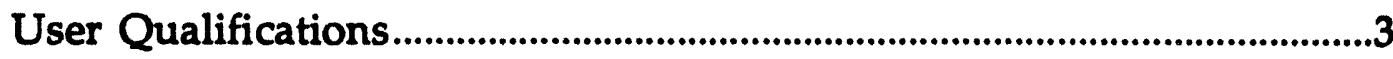

Discrepancy Reporting..........................................................................................4

Manual and Other Documentation.............................................................4

Task Plan Requirements ...................................................................................4

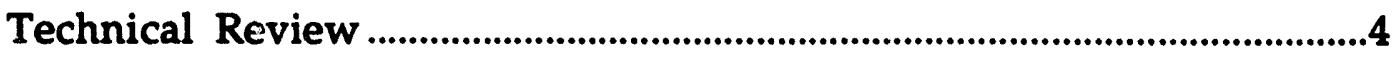

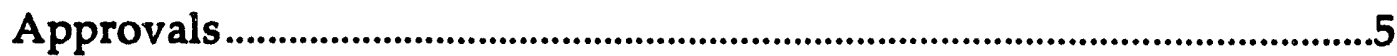

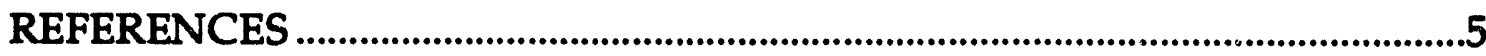

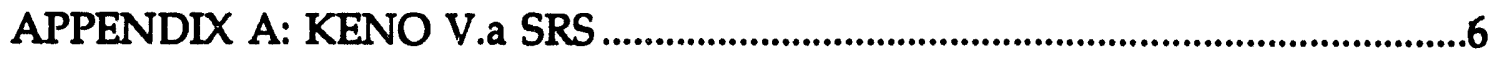

KENO V.a Software Certification Approval Form...............................................10 


\section{INTRODUCTION AND SUMMARY}

In response to a Department of Energy (DOE) request, Westinghouse Savannah River Company cominitted to certify all computer codes used in critical calculations at the site. The SCALE code system will be used at SRS to perform critical calculations related to nuclear criticality safety, and therefore must be certified.

SCALE is a modular code system for performing Standardized Computer Analyses for Licensing Evaluation.1 SCALE was developed for the Nuclear Regulatory Commission to satisfy a need for a standardized method of analysis for the evaluation of nuclear fuel facility and package designs. In its present form, the system has the capability to perform criticality, shielding, and heat transfer analyses using well established functional modules tailored to the SCALE system. SCALE was written at Oak Ridge National Laboratory (ORNL), and is currently maintained by the Radiation Shielding Information Center (RSIC). This Certification Package is for the KENO V.a module.

Certification as applied to existing computer codes includes the verification process, placing the code in configuration control, and establishing user qualification standards and training requirements. All software intended for use in critical calculations must be certified. This report is intended to fulfill the requirements for the certification of the KENO V.a module, part of SCALE 4.2, RSIC version C00545/IRISC/01, packaged 12/13/93, built at SRS March 18, 1994, by K. A. Niemer (executable version 1-2) on the RS/6000's in the SRTC UNIX Workstation Cluster.

Note that certification as defined here does not include the validation process. In the past, work performed by the Applied Physics Group was directly related to reactor safety or performance. This relatively narrow scope meant that defining validation requirements that would encompass all uses of the code was possible. In our new environment, APG performs criticality and shielding analyses. The variety of geometries, materials, and systems encountered is innumerable. For this reason, SCALE codes will be certified without validation. Validation will subsequently be performed for specific tasks that the codes are to be used for, using certified software. Thus certified software will be validated for specific tasks. Certification does imply that the code has been verified, placed in configuration management, and that all applicable documents as required in 1Q34 have been approved. Verification is accomplished by running the test problems included with the code, and comparing the results to those provided with the source code. Verification is documented in the test problem report.

This work was performed under STD task number 93-006-N-A-1 Rev. 1, SCALE 4.1 Criticality Code Certification, and follows the requirements of QAP IV-9 of 1Q34. 


\section{DISCUSSION}

\section{Application}

The KENO V.a module is a multigroup Monte Carlo criticality program used to calculate the k-effective of a 3-D system. ${ }^{2}$ Special features include simplified data input, supergrouping of energy-dependent data, the ability to specify origins for spherical and cylindrical geometry regions, a $P_{n}$ scattering treatment, extended use of differential albedo reflection, and an improved restart capability. KENO V.a is part of the SCALE modular code system. A complete discussion of the function of KENO V.a is given in Reference 2.

\section{Input}

KENO V.a data input features flexibility in the order of input. The singe restriction is that the title must be entered first and the parameter data, if any, mist immediately follow. KENO V.a may be run "stand alone" or as part of a SCALE criticality safety sequence. If KENO V.a is run "stand alone," cross-section data can be utilized from an AMPX ${ }^{3}$ working format library or from an ICE $^{1}$ mixed crosssection Monte Carlo format cross-section library. If KENO V.a is run as part of a SCALE criticality safety sequence, the mixtures are defined in the CSAS ${ }^{1}$ data and a mixing table data block cannot be entered in KENO V.a. A complete discussion of the input requirements is given in Reference 2.

\section{Output}

KENO V.a calculates the k-effective of a 3-D system. Other calculated quantities include lifetime and generation time, energy-dependent leakages, energy- and region-dependent absorptions, fissions, fluxes, and fission densities. A complete discussion of the output is given in Reference 2.

\section{Solution Method}

Details for the solution method of KENO V.a can be found in Reference 2.

\section{Accuracy and Limitations}

The accuracy of KENO V.a in calculating k-effective for particular types of problems will be addressed in the validation studies to be performed for those cases.

\section{Code Source Listing Location}

The source code for the SCALE 4.2 system, including KENO V.a, is stored under AFS on the SRTC UNIX workstation cluster, ${ }^{4}$ which protects it from unauthorized 
changes and ensures strict quality assurance standards are adhered to. The source files for SCALE 4.2 are stored in the /afs/srtc.srs.gov/project/crit/scale/src directory.

\section{Program Execution}

Instructions for executing the KENO V.a can be found in Reference 2. A set of twenty-five test problems has been developed which tests the major functions of KENO V.a. The input and output from these problems are detailed in References 2, 5, and 6. The test problem input can be found on the UNIX workstation cluster under AFS in the /afs/srtc.srs.gov/project/crit/scale/smplprbs/kenova file. The output is stored in the /afs/srtc.srs.gov/project/crit/scale/output/kenova.out file.

The executable module can be found on the UNIX workstation cluster under AFS in the /afs/srtc.srs.gov/project/crit/scale/exe directory, and scripts to execute KENO V.a in both an interactive and batch mode can be found in the /afs/srtc.srs.gov /project/crit/scale/scripts directory.

\section{Access Control and Security}

Access control and security of SCALE 4.2 on the SRTC UNIX workstation cluster is accomplished through the use of Access Control Lists (ACL) in AFS.7 Every directory in AFS has its own ACL that defines who can access the directory and its files. The SCALE proprietor maintains a scale-user group of authorized users who have read access to the /afs/srtc.srs.gov/project/crit/scale directory. Only those users labeled as cognizant on the proprietor's list may use the codes for critical calculations. Changes to the SCALE coding are made only by the proprietor, and are placed in production status after successful execution of the test problem set.

Technically knowledgeable personnel have been assigned to serve as code proprietor for the SCALE code system. These proprietors are members of the user community who are experienced users of the code.

A proprietor's code notebook 5 is being maintained in which an ongoing history of code development, alterations, validation, and error corrections is recorded. This notebook will be continually maintained by the code proprietor.

\section{User Qualifications}

User qualification status is divided into the two categories of Apprentice and Cognizant User, as defined in References 8 and 9. Due to the variety of problems for which KENO V.a may be used, a test will not be required to become a Cognizant User. Instead, the Apprentice will be trained by a Cognizant User. The code proprietor will determine when the Apprentice User has sufficient knowledge and understanding of the code to become a Cognizant User. Cognizant Users may be 
certified only for specific types of calculations or for all calculation types. A list of Apprentice and Cognizant Users will be maintained by the code proprietor.

\section{Discrepancy Reporting}

Cognizant users who find a discrepancy or apparent error in the KENO V.a coding, or who wish to request an upgrade/enhancement of the code, shall file an SCDR with the technical proprietor. The proprietor will report any errors to the code developers at ORNL via a numbered document mailed to RSIC and the developers. The proprietor will monitor the RSIC newsletter to see when bugs are found or a new version of the code has been released by ORNL.

\section{Manual And Other Documentation}

A user's manual ${ }^{2}$ for KENO V.a is in place that details code theory, input and output.

A controlled tracking system is in place to inform all cognizant users of coding and system changes in KENO V.a. All memoranda issued through this system are numbered and approved by management. The cognizant user list is maintained by the code proprietor.

A Software Requirements Specification (Appendices A) and a Software Test Plan were developed and approved by the appropriate personnel. A Software Baseline Status Listing is also maintained by the code proprietor which will be kept current as revisions and additions to the software documentation are made. All of these documents are maintained by the code proprietor in the task files, along with the task plan and the test problem report. ${ }^{6}$

\section{Task Plan Requirements}

All task deliverables as identified in the Task Plan 93-006-N-A-1, Rev. 2 with the exception of the SCMS entry form have been met and are stored as part of the official task records. The SCMS entry form was not applicable to the certification of KENO V.a on the SRTC workstation cluster since SCMS is not on the workstation cluster. AFS was used for configuration and control of codes on the workstation cluster. 4

\section{Technical Review}

A technical review of this document has been performed in accordance with QAP II14 of the 1Q34 Manual. The review sheets will be mainiained as part of the official task records. 


\section{Approvals}

The Certification Package Approval form has been signed by the required personnel and comprises the final page of this report.

\section{REFERENCES}

1. SCALE 4.2 Modular Code System for Performing Standardized Computer Analysis for Licensing Evaluation, RSIC Code Package CCC-545, Oak Ridge National Laboratory (December, 1993).

2. L. M. Petrie and N. F. Landers, "KENO V.a: An Improved Monte Carlo Criticality Program with Supergrouping," in SCALE 4.2 Modular Code System for Performing Standardized Computer Analysis for Licensing Evaluation, RSIC Code Package CCC-545, Vcl. II, Oak Ridge National Laboratory (December, 1993).

3. N. M. Greene, W. E. Ford, L. M. Petrie, J. W. Arwood, AMPX-77: A Modular Code System for Generating Coupled Multigroup Neutron-Gamma Cross-Section Libraries from $E N D F / B-I V$ and/or ENDF/B-V, ORNL/CSD/TM-283, October 1992.

4. K. A. Niemer and K. E. Hammer, Straw Man Proposal for Configuration and Control of APG Software on SRS Workstations (U), SRT-APG-940003, February 2, 1994.

5. K. A. Niemer, SCALE Certification Laboratory Notebook, WSRC-NB-94-139 (1994).

6. K. A. Niemer, KENO V.a Test Report (U), SRT-APG-940013, April 7, 1994.

7. AFS User's Guide, Transarc Corporation, Pittsburgh PA (1991).

8. J.E. Aull, Qualification of Apprentice Users, TP-90-304, April 15, 1991.

9. J.E. Aull, Qualification of Cognizant Users, TP-90-035, April 15, 1991. 


\section{APPENDIX A: KENO V.a SRS}

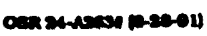

\section{Software Requirements Specification}

Title and Approval Page

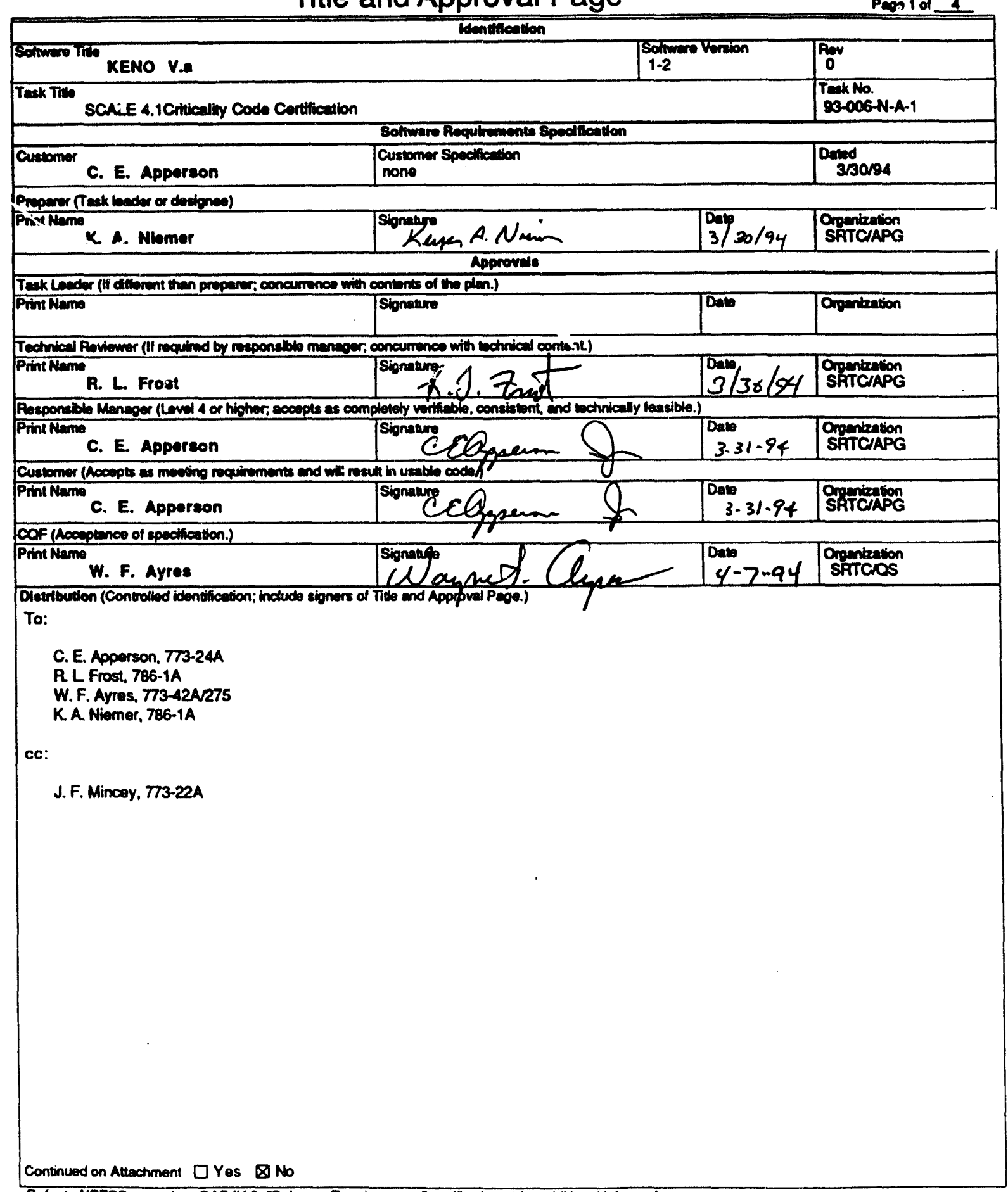

Reler to NATSC procedure OAP IV-3, "Sotware Requirements Specifications," Tor additional information. 


\section{KENO Va Software Requirements Specification}

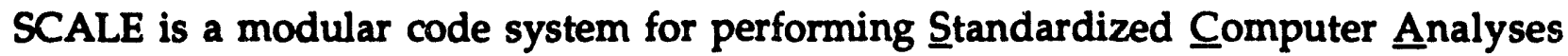
for Licensing Evaluation. ${ }^{1}$ SCALE was developed for the Nuclear Regulatory Commission to satisfy a need for a standardized method of analysis for the evaluation of nuclear fuel facility and package designs. In its present form, the system has the capability to perform criticality, shielding, and heat transfer analyses using well established functional modules tailored to the SCALE system. SCALE was written at Oak Ridge National Laboratory (ORNL), and is currently maintained by the Radiation Shielding Information Center (RSIC).

The KENO V.a module is a multigroup Monte Carlo criticality program used to calculate the k-effective of a 3-D system. ${ }^{2}$ Since KENO V.a is an existing code maintained by RSIC, this Software Requirement Specification was written with the existing capabilities, formats, and standards in mind.

\section{Function}

The primary purpose of KENO V.a is to determine k-effective. Other calculated quantities include lifetime and generation time, energy-dependent leakages, energyand region-dependent absorptions, fissions, fluxes, and fission densities.

\section{Performance and Attributes}

1. Time-related issues. Time-related issues are not applicable since running times are extremely problem and computing platform dependent.

2. Software environment. Since KENO V.a was written in FORTRAN-77, the code is portable. At SRS, KENO V.a is expected to be executed on the UNIX workstations. However, it could eventually be executed on the IBM 3090 or CRAY platforms.

Offsite, KENO V.a is maintained by RSIC. In order to install the code at SRS, the code proprietor acquires the software from RSIC and installs the software in a protected directory in AFS for protection and control. ${ }^{3}$ The code proprietor is also responsible for revising, testing, certifying and documenting the code.

The original source code from RSIC contains certain sections commented out which meet the requirements of a particular machine (UNIX workstation, IBM, or CRAY). In some instances, additional machine-dependent changes may be necessary for the code to execute on the SRS computing platforms. These changes will be documented with a Software Discrepancy/Change Report (SDCR). It is possible that there would be a version 1-0 for the IBM and a version 1-1 for the CRAY, and version 1-2 for the UNIX workstations. An appropriate set 
of the test problems will be run to ensure that the code performs correctly on each computing platform.

Changes and enhancements to the coding will be documented using SDCR's. An appropriate subset of the test problems will be run to ensure the code continues to perform correctly. Any required revisions to baseline documents will be made.

Since KENO V.a is maintained offsite, the certified SRS source may be subject to periodic upgrades as they are received from RSIC. Upon receiving the source, the proprietor will install the upgrade on the SRS platforms as described above.

Errors in the code found by users outside the SRS community are beyond our control. The following procedure is encouraged for error reporting/ reconciliation:

a) The error is reported to RSIC or the code developers.

b) The code developers fix the error and submit a new version of the code to RSIC.

c) RSIC makes the new version of the code available and notifies users via the RSIC Newsletter. (The SCALE proprietor receives the RSIC Newsletter monthly).

d) When the proprietor discovers that a new version of the code is available, the proprietor acquires the new source code, installs the upgrade on the SRS platforms as described above, and notifies users.

3. Tolerances. Tolerances on the results will not be addressed in this Software Requirement Specification since KENO V.a is an existing code.

Design constraints imposed on design and implementation phase activities

1. None. 


\section{External interfaces}

1. KENO V.a may be run "stand alone" or as part of a SCALE criticality safety sequence. If KENO V.a is run "stand alone," cross-section data can be utilized from an AMPX ${ }^{4}$ working format library or from an ICE ${ }^{1}$ mixed cross-section Monte Carlo format cross-section library. If KENO V.a is run as part of a SCALE criticality safety sequence, the mixtures are defined in the CSAS ${ }^{1}$ data and a mixing table data block cannot be entered in KENO V.a.

\section{Coding Standards}

1. KENO V.a was written at Oak Ridge National Laboratory (ORNL) to conform with FORTRAN-77 source coding standards.

\section{Dócuments}

1. The existing code documentation ${ }^{2}$ will satisfy the $1 Q 34$ requirements for a Software Design Report and User's Manual.

\section{References}

1. SCALE 4.2 Modular Code System for Performing Standardized Computer Analysis for Licensing Evaluation, RSIC Code Package CCC-545, Oak Ridge National Laboratory (December, 1993).

2. L. M. Petrie and N. F. Landers, "KENO V.a: An Improved Monte Carlo Criticaiity Program with Supergrouping," in SCALE 4.2 Modular Code System for Performing Standardized Computer Analysis for Licensing Evaluation, RSIC Code Package CCC-545, Vol. II, Oak Ridge National Laboratory (December, 1993).

3. K. A. Niemer and K. E. Hammer, Straw Man Proposal for Configuration and Control of APG Software on SRS Workstations (U), SRT-APG-940003, February 2, 1994.

4. N. M. Greene, W. E. Ford, L. M. Petrie, J. W. Arwood, AMPX-77: A Modular Code System for Generating Coupled Multigroup Neutron-Gamma Cross-Section Libraries from ENDF/B-IV and/or ENDF/B-V, ORNL/CSD/TM-283, October 1992. 
$00224177000-5011$

\section{Software Certification Approval Form}

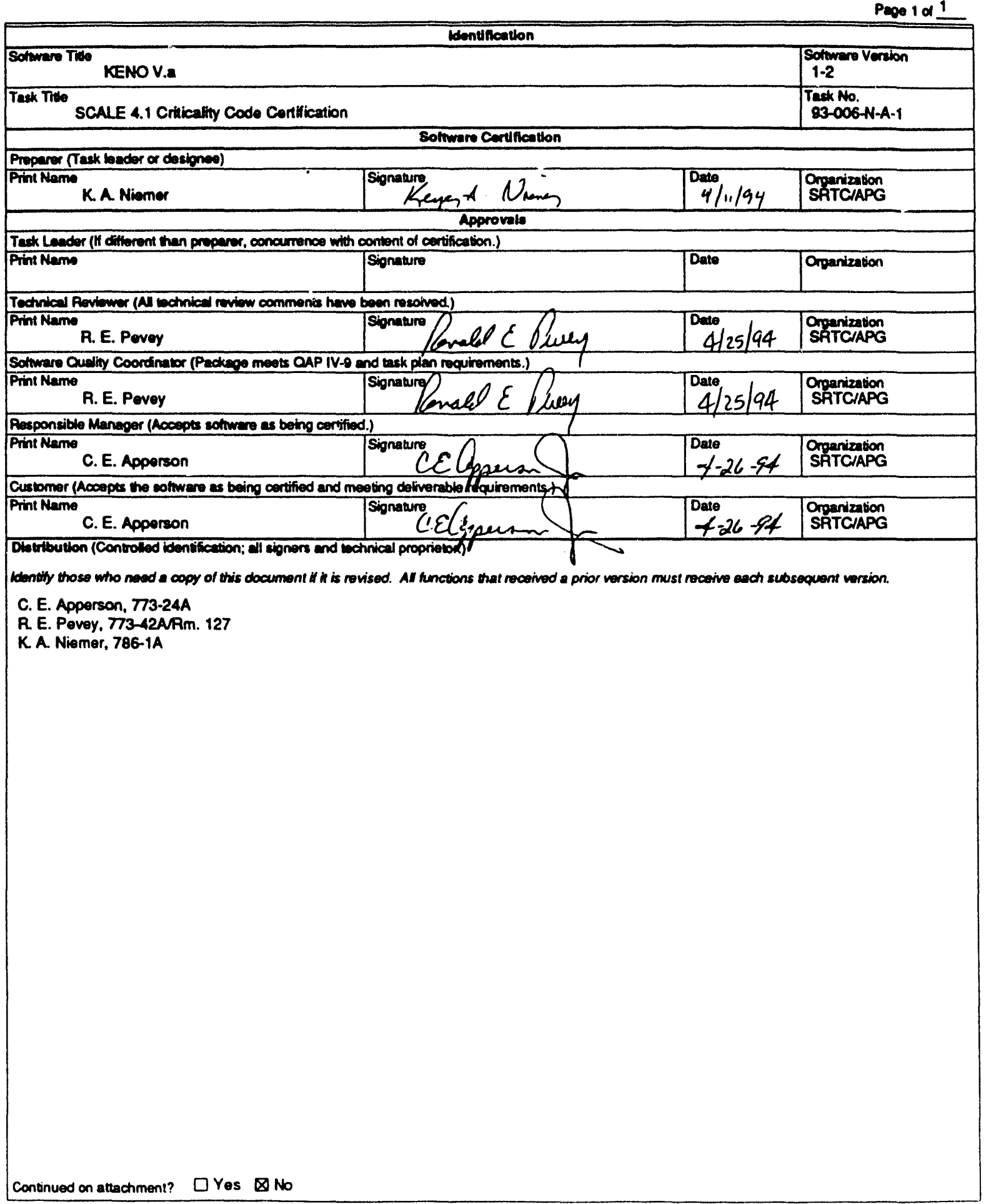

\footnotetext{
Refor to NATSC procedure OAPIV-9, "Software Certification," for additional information
} 

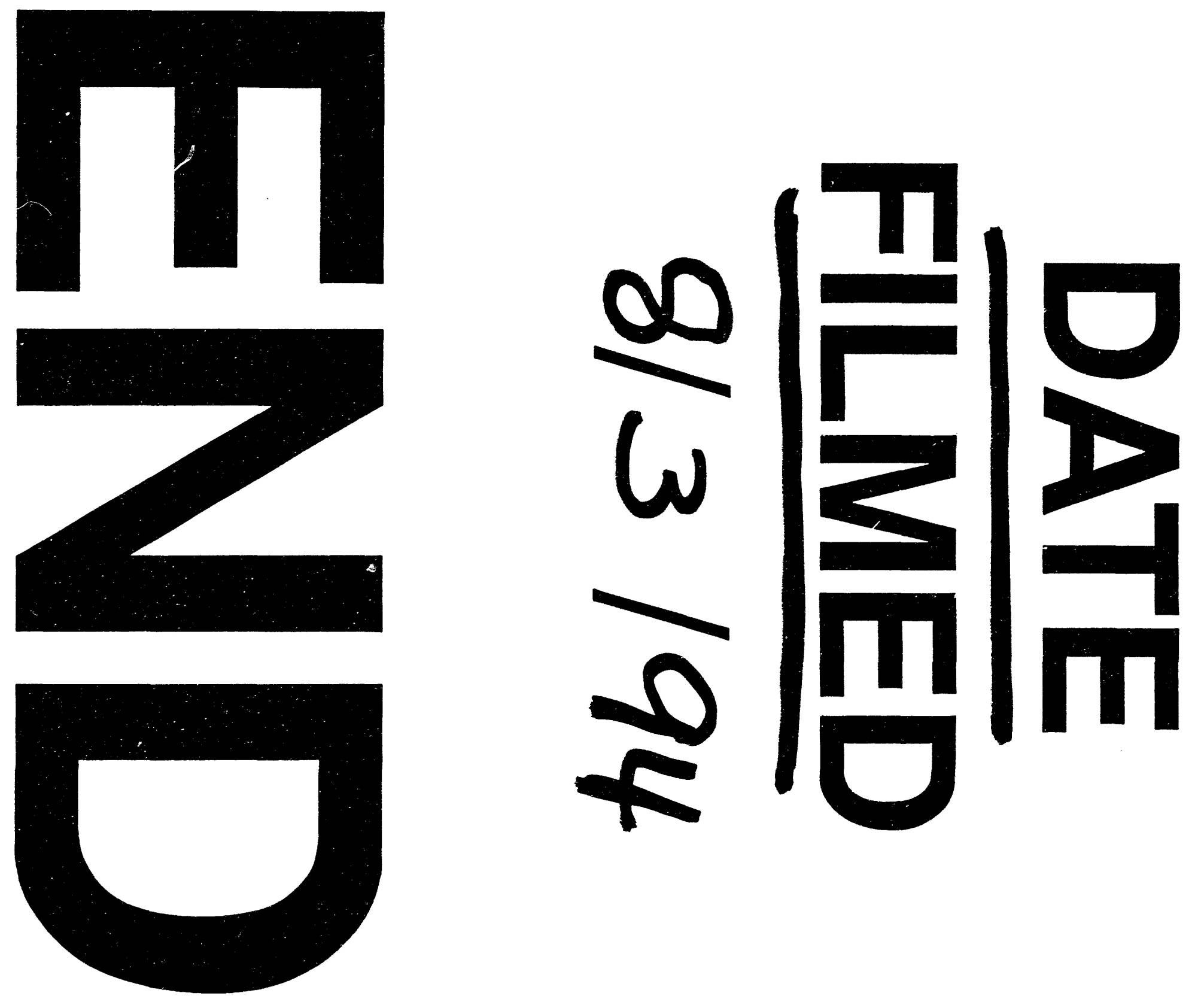
